\title{
A Special Issue on Geothermal Energy and Its Application
}

\author{
Kewen $\mathrm{Li}^{1,2}$
}

Published online: 26 March 2019

(C) International Association for Mathematical Geosciences 2019

It is a great pleasure to introduce this Special Issue of Mathematical Geosciences on "Geothermal Energy and its Application", dedicated to all the members of the worldwide geothermal and related communities.

The extensive consumption of fossil-based energy has caused serious environmental and ecological problems that impact the economy and our lives. The ongoing massive dependency of the worldwide industry and our daily activities on fossil fuels will continuously increase the rate of global warming with disastrous consequences. Not only do future energy sources need to be clean and renewable, they also need to be robust. One of the possible solutions to problems caused by fossil-based energy may be the large-scale utilization of renewable energy such as geothermal energy.

Geothermal energy has many advantages compared to other renewables. Such advantages include: (1) it is unaffected by weather; (2) it is a flexible and base-load power; (3) it is stable and has a high capacity factor (over $90 \%$ in many cases); (4) it requires less land and has less of an ecological effect; (5) it has high thermal efficiency; and (6) it is clean and local.

In recent years, great advances have been achieved in resource assessment, reservoir modeling, geology, geophysics, geochemistry, and other areas of geosciences related to geothermal energy. These achievements have contributed to the fast growth of the geothermal industry. In light of the great evolutions witnessed in the industry, the goal

\footnotetext{
$\bowtie \quad$ Kewen $\mathrm{Li}$

likewen@cugb.edu.cn

1 School of Energy Resources, China University of Geosciences (Beijing), 29 Xueyuan Road, Beijing 100083, China

2 Stanford Geothermal Program, Stanford University, Stanford, CA 94305-2220, USA
} 
of this Special Issue is to showcase some of the recent contributions of methods and theories that are relevant to the geosciences of exploring and developing geothermal energy. To this end, six papers have been selected from the 7th Annual Conference for the Development and Utilization of Geothermal Energy held in Beijing, China, March 26-28, 2018.

The first of the six papers in this Special Issue is by Shejiao Wang, Junwen $\mathrm{Hu}$, Jiahong Yan, Feng Li, Ningsheng Chen, Qi Tan, Bincheng Guo, and Lufeng Zhan who conducted an assessment of geothermal resources in petroliferous basins in China. The geothermal industry has been struggling there for many years as the total installed capacity of geothermal electricity has been eclipsed by solar and wind in recent years. The authors argue however, that an enhanced geothermal system (EGS) may be the most promising initiative over the longer term as the co-production of geothermal energy from petroleum formations may be a type of resource that could convert into real power capacity in the near term. The authors demonstrate that the petroliferous basins are very rich in geothermal resources. The annual recoverable resources reach is $1.626 .8 \times 10^{6}$ tons of standard coal. Thus, the development and utilization of the geothermal energy in oilfields has a huge potential for both power generation and direct use, which is of great significance for the green development and life extension of oil fields.

The development of deep geothermal energy usually has a high risk from an economic point of view because it is difficult to determine the temperature and its distribution at a great depth in a geothermal reservoir. The temperature is affected by many factors including heat sources, heat transfer mechanisms, fluid flow systems, heterogeneity of geological units, etc. The estimation of sub-surface temperature relies on a clear understanding of geological structures and the related parameters such as radiogenic element concentration, thermal conductivity, and rock density. Hejuan Liu and Mather Nasr found that an evaluation of the deep geothermal potential merely based on the surface heat flux may overestimate or underestimate the geothermal capacity because of possible major differences between surface and sub-surface heat flux. Consequently, this may result in a significant increase of economic risk in geothermal development.

Biao Shu, Ming Liang, Shaohe Zhang, and Jeffrey Dick utilized a flat-joint model (FJM) in a three-dimensional particle flow code to examine the effect of heterogeneity on the micromechanical properties of granite. The results indicate that the microparameters of the FJM significantly influence the rock mechanical properties.

Cooling is a big issue for geothermal power generation. Natural draft dry cooling towers (NDDCTs) may be used as a type of cooling facility in geothermal power plants. They are receiving increasing preference from the industry for their water saving advantages. Inlet airflow pre-cooling using water spray might be one viable method for reducing the negative impact of the ambient temperature on the performance of NDDCTs. However, the benefit has not yet been concretely verified. To fill this gap, Christo Nel, Zhiqiang Guan, Yuanshen Lu, and Kamel Hooman experimentally examined three different water sources: fresh water, artificially-simulated saline water, and real coal seam gas well water. They confirmed that there was an increase in the cooling efficiency of the spraying system when artificially-simulated saline water was used as the water source. 
Yong Jiang, Yalin Lei, and Jing Liu constructed an input-output model for the geothermal sector within the overall economy based on the data from Beijing, China. Their results and related analysis support the existence of the relationships between the geothermal sector and other economic sectors in Beijing. Their work also shows that the demand for geothermal resources varies widely among different industrial sectors of Beijing's economic system.

The Special Issue concludes with the topic of utilizing shallow geothermal energy for space heating. In this paper, Guoxiang Zhao, Kewen Li, Changwei Liu, and Lin Jia developed a new space heating system coupled with an underground energy storage system. Their simulation results proved that it is possible to meet human indoor space heating demand by using the space heating system without installing heat pumps. Because of the inherent advantages of simplicity, low cost, and reliability, this new technology for geothermal space heating may have a promising future.

I hope you will enjoy the papers of this Special Issue!

The Guest Editor 